\title{
Empirical study with structural break on the relationship between financial development and economic growth of Jiangxi province
}

\author{
Xinxi Jiang \\ Professor of Business school, Jiangxi Normal University, Nanchang, Jiangxi, China \\ Xizhi Luo \\ Postgraduate of International Education School, Jiangxi Normal University, Nanchang, Jiangxi, China
}

\begin{abstract}
The empirical study over the period 1978-2011 found that the relationship between real per capita GDP and financial interrelation ratio structurally broke since 2004. From 1978 to 2003, economic growth and financial development had a long-term co-integration, and it showed one-way supply relationship according to the Granger causality test, which means the economic growth have a slowly leading function to the development of finance. From 2004 to 2011, the correlation between them became weaker and had no Granger causality, but there had a long-term co-integration and mutual causality relationship existed between loan and GDP during the whole period. From it we can see loan could boost output more persistently. Therefore, the enhanced economic power of Jiangxi province could promote further development of regional financial service industries, and we would propose some related policy suggestions in this paper.
\end{abstract}

Keywords: financial development; economic growth; structural break; Jiangxi province

\section{INTRODUCTION}

Finance is the heart of modern economy, the relationship between financial development and economic growth has been a hot topic in theory circle. Since 1960, the financial structure theory of Goldsmith, Mackinnon-Shaw's financial deepening theory, and King \& Levin (the representative of the financial development of the empirical and theoretical studies) all pointed out that the financial development has the function of promoting economic growth. The empirical research of scholars in China began in 1999, such as the study of the national financial intermediaries, stock market development and economic growth of Luyong Tan. Most of the results show that Chinese financial development is proportional to economic growth and the economic growth and financial development could promote each other. But from the empirical research of regional economy, we found that the progress of financial development may not have a positive effect on regional economic growth, for example, Liuyi Xiao and Weidong Zhang believe that the level of financial development in all provinces of China is inversely related to the economic growth rate.
Therefore, we must pay more attention on the relationship between regional financial development and economic growth. Regard to Jiangxi province, the midland developing economic entity, it has important theoretical and practical significance to correctly analyze the relationship between economic and financial development in order to promote a healthy development of economy in Jiangxi province. Feng Chen, Jinhua Yuan, Jun Xu, Minxia Wu and Tingting Zhang (2006) made an empirical analysis on the loans and GDP of Jiangxi Province, but they haven't inspected the stability and co-integration relationship of variables, thus we cannot eliminate the senseless correlation and spurious regression problems exist between variables. And also the establishment of positive correlation cannot represent the existence of a causal link. What's more, the macro economic variables often have problems of structural break, the general linear model and test is invalid. Therefore, it is completely necessary to consider the empirical research on the relationship between regional finance and economy under the structural break.

This paper intends to study the long-term relationship between the loan balance and the GDP, the finan- 
cial correlation and the per capita GDP of Jiangxi Province from 1978 to 2011. Among them, the real growth rate, and population data from 1978 to 2011 are all from the Jiangxi Provincial Bureau of Statistics Yearbook (2010) and Jiangxi Provincial Bureau of Statistics online. The gross national product, the actual growth rate and population data are selected from the National Bureau of Statistics Network station. Jiangxi RMB deposit and loan balance (1978-2005) are from the financial database in People's Bank of Nanchang Center branch. Data during the period 2006-2011 come from the Jiangxi Provincial Bureau of Statistics website. National RMB deposit and loan data (1978-2009) derive from the China Statistical Yearbook 2010 on homepage of National Bureau of Statistics. And data from 2010 to 2011 are from the website of People's Bank of China. This empirical study adopts Eviews 6.0 software, and the empirical results are not less than 0.05 level.

\section{THE RELATIONSHIP BETWEEN FINANCIAL CORRELATION AND REAL PER CAPITA GDP IN JIANGXI PROVINCE.}

\subsection{Index selection}

This paper selects annual financial correlation index from1978 to 2011 (Financial Interrelations Ratio, FIR) and natural logarithm of GDP in Jiangxi province to represent respectively the financial development and economic growth. Financial correlation (FIR) is the proportion of financial assets and physical assets stock. Because of the indirect financing accounted for the main part in Jiangxi province, it is appropriate to use deposits and loans and the proportion of GDP to measure the level of financial development. The natural logarithm of real per capita GDP use 1978 as the base period, and after the real GDP growth rate of fixed based annual being calculated, we can obtain the total annual real GDP which is divided by the total population. At last the real per capita GDP is obtained, and then took the natural logarithm from it to eliminate the influence of heteroscedasticity in price and demographic factors.

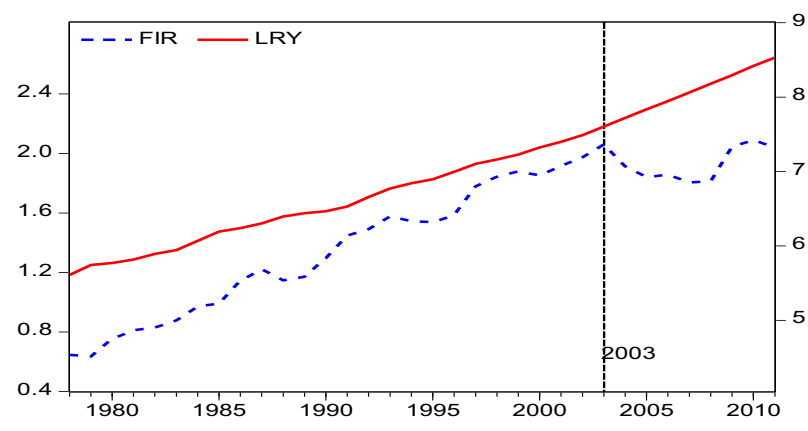

Figure 1. Financial correlation FIR and per capita output LRY in Jiangxi province (1978-2011)
It is a common phenomenon in the study of time series that the macroeconomic which has the feature of time trend appears a structural break on the basis of time. From observing the FIR and LRY in Figure 1, we can conclude that when following the passage of time, real per capita output (LRY) were continuous growing, while the financial correlation degree (FIR) emerged a significant change after 2003 that showed a horizontal fluctuation. Therefore, we should consider a structural break in the premise of linear model, and it can be divided into two periods for study.

\subsection{Inspection on single structural break}

This paper used dummy variable method of Zhizhuang Zhou, which can not only test whether the structural breakpoints hypotheses in 2004 can be established or not, but also can figure out the characteristic of structural break which was caused by intercept term, slope, random shocks or these three.

\subsubsection{Hypothesis test of single structural break}

Assuming that the financial correlation and the per capita GDP have a linear correlation, and the structural break changed since 2004, we could obtain some possible reasons as follows: 1) transient fluctuations are caused by the random shock of macro-control policy; 2) drift of intercept term; 3) slope, and the reason can also be the combination of these three. In this paper, we choose the method of dummy variable to test the structural break aroused by random shock, drift and slope. The model of a structural break with these three dummy variables is included below.

$\mathrm{Y}=\alpha+\beta_{1} \times \mathrm{X}+\beta_{2} \times D L+\beta_{3} \times D L \times X+\beta_{4} \times D P+\varepsilon_{T}$

In formula (1), $\mathrm{Y}$ is interpreted as a variable, $\mathrm{X}$ is the explanatory variable, $\alpha$ is intercept term, $\beta_{\mathrm{i}}$ is regression coefficient, DL is level dummy variable, DP is the random shock of dummy variables, and $\varepsilon_{\mathrm{t}}$ is random error. When the regression coefficient of the dummy variable is significantly different from zero at the 0.05 level, it can be considered that the influence of the structural break or random impact is obvious, otherwise it cannot exist. Then remove the dummy variable to make a continuous regression, and keep removing until all the estimated parameters and equations have been tested at the 0.05 significant level.

Suppose FIR is the explained variable, LRY is the explanatory variable, and the DL is dummy variable which could reflect the structural break since 2004, there $\mathrm{DL}=0$ for the observation from 1978 to 2003 and the rest is 1 . At the same time, suppose the virtual variable DP represents the random shock of macroeconomic and financial control policy, then select 1987 , 1991, 1993, 1997, 2004, 2010 as the impact point, $\mathrm{DP}=1$, and the rest time point $\mathrm{DP}$ value is 0 .

According to the model (1), the test equations of FIR structural break as follows: 
$F I R=\alpha+\beta_{1} \times L R Y+\beta_{2} \times D L+\beta_{3} \times D L \times L R Y+\beta_{4} \times D P$, the variable conclusion after regression can reference to Table 1 .

Table 1. The estimated result of structural break equation parameter

\begin{tabular}{l|llll}
\hline $\begin{array}{l}\text { Model } \\
\text { parameter }\end{array}$ & $\begin{array}{l}\text { Estimated } \\
\text { value }\end{array}$ & $\begin{array}{l}\text { Standard } \\
\text { deviation }\end{array}$ & t-statistics & Prob. \\
\hline$\alpha$ & -3.4741 & 0.1194 & -29.092 & 0.0000 \\
$\beta_{1}$ & 0.7308 & 0.0181 & 40.319 & 0.0000 \\
$\beta_{2}$ & 2.9388 & 0.5983 & 4.912 & 0.0000 \\
$\beta_{3}$ & -0.4312 & 0.0744 & -5.799 & 0.0000 \\
$\beta_{4}$ & 0.1071 & 0.0246 & 4.358 & 0.0002 \\
\hline
\end{tabular}

Coefficient of determination $\mathrm{R}^{2}=0.988$; D.W. $=1.942$; statistic of $\mathrm{F}$ is 597.8 , it is remarkable on the average 0.01 level. Then testing the regression residuals by serial auto-correlation $\mathrm{Q}$ test, and the lag 16 phase residual error have no auto-correlation. Choose the ADF information criterion to test the AIC unit root of the form $(0,0,2)$ which showed that the residual have no unit root, it is a stationary process of I (0), and its regression model can pass test. Then the regression equation can be divided into two period linear regression equations as follows:

Regression equation from 1978 to 2003 :

$F I R=-3.4741+0.7308 L R Y+0.1071 D P$

Regression equation from 2004 to 2011 :

$$
F I R=-0.5353+0.2996 L R Y+0.1071 D P
$$

In view of the parameter estimation value, the financial correlation of Jiangxi province occurred intercept structural broke and slope structural broke since 2004, which led to the enlargement of intercept term and the decrease of slope; The random shocks brought from macro-control monetary policy is positive to the financial correlation regression coefficient, thus it can indicate that in the entire period, these random shock could increase Jiangxi financial correlation.

\subsection{FIR and LRY's Granger causality test}

Because the test of Granger causality require a stable variable, thus it is necessary to test the stability of variables. From the ADF unit root test, in the period from 1978 to 2011, FIR is I (1) variable, LRY is I (2) variables, during the whole period, we found the FIR and LRY have no Granger causality. And then we divided it into 1978-2003 and 2004-2011 these two periods to further examine the causal relationship.

\subsubsection{During the period from 1978 to 2003}

First of all, test the stability of variables. ADF unit root test still takes the information criterion of AIC, which is maximum lag 5 periods. The results is shown in Table 2, which shows that the FIR and LRY in this period are all I (1) single integer variable.

Table 2. The result of ADF unit root test

\begin{tabular}{l|lll}
\hline Variable & Inspection form & t-statistics & stability \\
\hline FIR & $(\mathrm{c}, 0,5)$ & -0.8272 & Non stable \\
$\Delta$ FIR & $(\mathrm{c}, 0,4)$ & $-6.8042 * * *$ & stable \\
LRY & $(0,0,4)$ & 3.951 & Non stable \\
$\Delta$ LRY & $(\mathrm{c}, 0,3)$ & $-3.922^{* * *}$ & stable \\
\hline
\end{tabular}

Note: Inspection form ( $C, t, P)$, respectively indicated the constant term, trend term and lag periods of unit root test equation, if the $\mathrm{c}$ and $\mathrm{t}$ are zero, it means that the variable have no constant term or trend item; $\Delta$ is difference operator; ${ }^{*}$ means the test statistic is significant at 0.1 level. ${ }^{* *}$ indicates it is significant at 0.05 ; and $* * *$ means it is significant at the 0.01 level.

Secondly, according to the information criterion of $\mathrm{SC}$, choose the optimal lag period for the FIR and LRY, and then we can obtain the result that vector auto-regressive (VAR) is phrase 1. Depending on the criticality value of the MacKinnon-Haug-Michelis (1999), choose the inspection form those which have no intercept and trend under the condition of VAR $(1,1)$, the statistic of co-integration test and the maximum eigenvalue statistics of Johansen show that at the 0.05 level they have co-integration relationship, and estimate the equation is FIR $=0.725 \mathrm{LRY}$ or LRY $=$ 1.379FIR. From a further Granger causality test on the FIR and LRY after stability, we found that the LRY and FIR have no Granger causality from phrase 1 to phrase 5 lag, and phrase 7 lag above, which means they are independent of each other. The test results of phase 6 lag is shown in Table 3 .

Table 3. The result of Granger causality test between LRY and FIR

\begin{tabular}{l|lll}
\hline $\begin{array}{l}\text { Lag } \\
\text { period }\end{array}$ & Null hypothesis & F-statistics & estimate \\
\hline \multirow{3}{*}{6} & $\begin{array}{l}\Delta \text { LRY is not the } \\
\text { Granger reason of } \Delta \text { FIR }\end{array}$ & $9.905^{* * *}$ & Refuse null \\
& $\Delta$ FIR is not the Granger & 1.196 & $\begin{array}{l}\text { Accept null } \\
\text { hypothesis }\end{array}$ \\
& reason of $\Delta$ LRY & & hypothes \\
\hline
\end{tabular}

The results of this test show that the per capita real output is the Granger reason of the financial correlation degree, but the financial correlation is not the real Granger reason of per capita GDP. From 1978 to 2003 financial development and economic growth appeared a weak one-way causal relationship, that is, economic growth promotes financial development slowly.

\subsubsection{4-2011 period}

As for the FIR and LRY from 2004 to 2011, test results of ADF unit root indicate that LRY and FIR were I (1), I (2) process respectively, both of which had no direct co-integration relationship. After the stability, 
the Granger causality test shows that there is no significant Grainger causality relationship between them. In the form of $(0,0,0)$ test equation, the residual error is I (0) variables, and have no auto-correlation, so there may exist a multivariable co-integration relationship among the FIR, LRY and DP, but because it is a short period, and there are only eight samples, we cannot continue to test.

\section{GE CO-INTEGRATION TEST ON THE RELATIONSHIP BETWEEN TOTAL CREDIT AND GROSS DOMESTIC PRODUCT}

\subsection{The co-integration test on the loan balance and the total output value}

Select year-end RMB deposit balance (LOAN) and gross domestic product (GDP) in Jiangxi province from 1978 to 2011 in order to test their relationship, and then we can see there is a linear correlation between them, which can be found from the scatter plots in Figure 2.

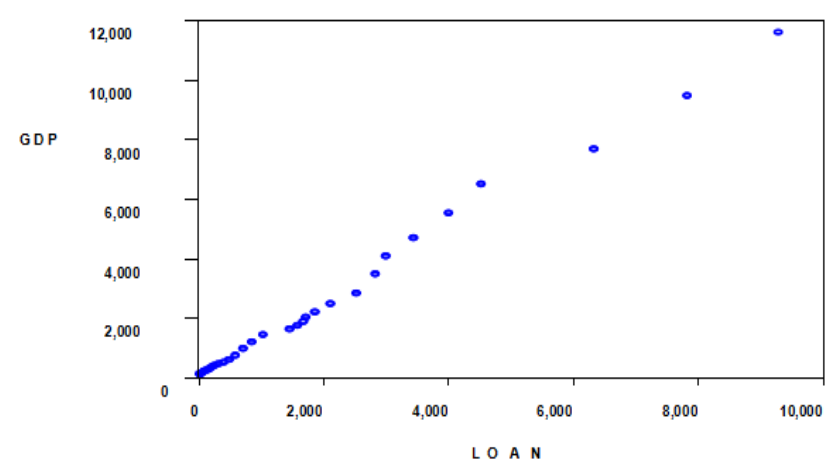

Figure 2. A scatter diagram about the function of gross domestic value (GDP) on loan balance (LOAN) in Jiangxi province

Adopt the GE two-step co-integration test. The principle is if the residual of these two variables is stationary after linear regression, it can indicate that they have a co-integration relationship. Made an OLS regression with the gross domestic value as the dependent variable and the loan as the explanatory variable, we can reach a conclusion after remove indistinctively constant term as follows.

$$
\begin{aligned}
& \mathrm{GDP}=1.247 \mathrm{LOAN} \\
& \mathrm{SE}=(0.014) \\
& \mathrm{R}^{2}=0.994 \quad \text { D.W. }=1.00
\end{aligned}
$$

Made an ADF stability test on the residual, AIC information criterion selected phase 6 lag and haven't have intercept term. The result is not the null hypothesis (it had no unit root) at the 0.05 level, that is to say the residual sequence is stable. Therefore, it indicates that there exists a co-integration relationship between loan and GDP. In view of the residual have auto-correlation, the error of the estimated coefficient of ordinary OLS regression is larger, so we think it can effectively improve the accuracy of the model by adding the AR (1) model, and also can eliminate the auto-correlation of the residual error. Modified OLS model as follows.

$$
\begin{aligned}
& \mathrm{GDP}=1.2393 \mathrm{LOAN}+[\mathrm{AR}(1)=0.5097] \\
& \mathrm{SE}=(0.022) \quad(0.156) \\
& \mathrm{R}^{2}=0.995 \quad \mathrm{DW}=1.764
\end{aligned}
$$

\subsection{The Granger causality test of LOAN and GDP after differential stability}

Due to the Granger causality test for non-stationary variables may make mistakes, three difference stability tests on GDP and LOAN are made which are both in the third-order single integer variables, and obtain the stationary variables $\Delta^{3}$ LOAN and $\Delta^{3}$ GDP and then test again. The 1-4 phase lag divisor was selected and the results are shown In Table 4.

It is not the null hypothesis of the GDP Granger reason because it refuses to loan while the result of this test is above 0.05 level, and negate the null hypothesis under the phrase 1 and 4 lag conditions, accepting the null hypothesis under the phrase 2 and 3 lag. In fact, while the lag period extended to more than 5 phase, they both showed a bidirectional Granger causality above the significant 0.05 level. It is visible to see that the loan and economy under the phase 1 lag conditions showed the bidirectional causality, that is, economic growth can promote loan demand and the supply of loan can promote economic growth simultaneously. Nevertheless, in the case of phrase 2 and phrase 3 lag, these two are one-way causality, which means that the economic growth does not promote loan, but loan promotes economic growth. So if the elasticity of the loan output value is $1.239,1 \%$ of the

\begin{tabular}{|c|c|c|c|c|}
\hline Null hypothesis & Phrase 1 lag & Phrase 1 lag & Phrase 1 lag & Phrase 1 lag \\
\hline$\Delta^{3} \mathrm{LOAN}$ is not the Granger Reason of $\Delta^{3} \mathrm{GDP}$ & $20.536 * * *$ & $10.167 * * *$ & $7.349 * * *$ & $13.913 * * *$ \\
\hline$\Delta^{3} \mathrm{GDP}$ is not the Granger Reason of $\Delta^{3} \mathrm{LOAN}$ & $11.950 * * *$ & 1.025 & 0.893 & $3.044 * *$ \\
\hline
\end{tabular}
loan growth can bring about $1.239 \%$ of GDP growth.

\section{RELATED CONCLUSION AND POLICY RECOMMENDATIONS}

The relationship between financial development and

Table 4. The F-statistics of Granger causality test on $\Delta^{3}$ LOAN and $\Delta^{3}$ GDP 
economic growth showed a great difference due to the difference of region and development stage. From the empirical results of Jiangxi province, the financial development and economic growth have two different relationships because of the occurrence of significant structural broke since 2004, thus we can reach a conclusion that the real per capita output and financial correlation had a long-term co-integration relationship from 1978 to 2003, and they appeared a highly positive correlation of each other. As for the relationship between financial development and economic growth, they have a long-term supply relationship but the lag period is longer, that is to say the economic growth plays a negative role in promoting financial development, and financial correlation has no significant role in promoting economic growth. While during the period between 2004 and 2011, the correlation between them had been greatly reduced. What' s more, regard to the relationship between loan and total output, we can see during the whole period 1978-2011, the loan and economic growth of financial intermediation had a co-integration relationship, they have a relationship of linear positive correlation. The Granger causality test shows that there is a two-way causal relationship in them, which the loan could further supports economic growth. In the paper, the regression model also shows that the marginal output of Jiangxi province reached 1.24 , which is higher than the average level (about 0.85 ) over the same period.

From the point of view in the whole country, the level of the monetization and financial economic system of Jiangxi province is lower than the national average standard, and the gap between the eastern developed regions is greater. It is a kind of financial and economic equilibrium state in a lower financial development level. From 2005 to 2011, Jiangxi loans accounted for an average of $0.7687 \%$ of GDP, $28.7 \%$ lower than the national level of $1.0786 \%$; deposits accounted for $1.1582 \%$ of GDP, $28.1 \%$ lower than the national level of $1.6111 \%$; loan accounts for $0.6639 \%$ of deposit, which close to the national level $(0.6694 \%)$, and the gap is less than $1 \%$. It reflects that the efficiency of local financial intermediation has been reached a better level, the efficient operation of financial intermediaries and the full supply of loans could promote the economic development. In recent years, the real economic growth rate in Jiangxi province is strong. The real growth rate of GDP reached $14.8 \%$, which is higher than the national level of $10.91 \%$ and the financial correlation is $1.9269 \%, 28.4 \%$ lower than the national level of 2.6897 . We can conclude that the rapid economic growth of Jiangxi province hasn't put the high level of financial development as the premise, but it could lead the financial development slowly.

In this paper, we can see there has a good opportunity for the financial service industries if economic growth of Jiangxi province could maintain a sound and fast level. So I want to suggest that on the occasion of the next National Twelfth Five-year Plan period, Jiangxi should vigorously enhance the level of financial services, and raise funds from multiple channels to support the demand of eco-friendly economic development; to enhance the proportion of deposits and supply loans under the premise of the given bank's asset liability ratio. We should pay full attention to the role of direct financing to encourage and facilitate the local enterprises to issue bonds and stocks for direct financing, in order to lead the structural upgrade of financial industry. Simultaneously, to increase the construction of insurance, trust, securities, financial institutions and other nonbank financial institutions. And also establish industry funds, accounting firms, financial institutions and other integrated three-dimensional patterns to form a certain depth of regional financial market.

\section{REFERENCES}

[1] Ruyong Tan. 1999. The empirical study on the relationship between Chinese financial development and economic growth. Economic Study, (10): 53-61.

[2] Liuyi Xiao, Weidong Zhang. 2006. The paradox between financial development and regional economic growth. Financial and Economy, (7): 3-6.

[3] Feng Chen, Jinhua Yuan, Jun Xu, Xia Wu, Tingting Zhang. 2006. The empirical study on the relationship between financial credit growth and economic development in Jiangxi Province--Compare with the Shanxi Province. Financial and Economy, (12): 41-45. 